\title{
Reliability Analysis for the Food Manufacturing Industry
}

\author{
Israel de Carvalho Lino ${ }^{1}$; Karla Patricia Santos de Oliveira Rodriguez Esquerre'; \\ Angelo Marcio Oliveira Sant'anna ${ }^{2 *}$ \\ ${ }^{1}$ Federal University of Bahia, Industrial Engineering Graduate Program; \\ ${ }^{2}$ Federal University of Bahia, Polytechnic School; Salvador, Bahia, Brazil
}

\begin{abstract}
The present study aims to analyze the main reliability measures for packing equipment used in the production process of corn chips. The Anderson-Darling test was used to evaluate the best distribution of the data collected, showing the lognormal distribution as the best model for the data. We used the Minitab v.17 software for the probability functions of some statistical models. The results showed an MTTF indicator at 2.5 days and $R(t)=0.47$. Furthermore, the packaging equipment depends on maintenance actions having only a $47 \%$ chance of not failing when in operation.
\end{abstract}

Keywords: Reliability. Lognormal. MTTF. Hypothesis Test.

The globalized economy and the relentless chase of recovery from the economic crisis have demanded companies to have a higher degree of control. So, the organizations have sought new management tools that point to greater competitiveness through the quality and productivity of products, processes, and services [1].

The goal of better management is always to seek higher profitability, cost-reduction, increase productivity, promoting the company's growth and competitiveness in a short-time. So, growing productivity implies a better use of employees, machines, energy, and fuel consumed raw materials, and other issues [2].

The data presented implies the vulnerability of the productivity indicator. The impact caused by equipment failures was discussed in this paper, evaluating the Reliability Centered Maintenance (RCM) management scenario. The data was organized in Pareto graphs to determine the most significant impact per machine and higher call opening demand; then, the data was applied to the probability of failure functions to know which model has the best data behavior and, hence,

Received on 27 August 2019; revised 23 September 2019. Address for correspondence: Dr. Angelo Marcio Oliveira Sant'anna. E-mail: israel.lino@outlook.com. This study was selected from the V International Symposium of Innovation and Technology - SIINTEC (October 2019).

J Bioeng. Biotech. Appl. Health 2019;2(3):80-85.

(C) 2019 by SENAI CIMATEC. All rights reserved. apply the data to the reliability function $\mathrm{R}(\mathrm{t})$ and MTTF.

This article aims to analyze the reliability and the meantime of the machine's flaw that most imply the failures of the production line. So, the maintenance department will be able to direct the efforts and actions to correct the points in order to re-measure the indicators and confirm their evolution or not.

\section{Reliability-Centered Maintenance}

Reliability-centric maintenance refers to a maintenance program designed to return the equipment's inherent production capacity [3]. The primary purpose of maintenance is to maintain and improve the reliability and regularity of the production system's operation [4].

Siqueira [5] reports that the RCM incorporates new maintenance and monitoring techniques, as well as absorbs modern statistical optimization methods developed by production engineering. One of the advantage of this system is the establishment of a structured way to select maintenance activities.

The production system has a few failures. So, the reliability and availability of machines and equipment increase the point to be solved. For $\mathrm{Xie}$ and colleagues [6], the failures in a regular operation system are random events caused by a sudden increase in stress or human error. 


\section{Key Reliability Indicators and Functions}

The time to fail, measured from the time the unit is commissioned to fail, is defined by the equation:

$$
F(t)=P(T \leq t)=\int_{0}^{t} f(u) d u, t>0
$$

The equation that defines the reliability is:

$$
R(t)=\frac{n_{S}(t)}{n_{S}(t)+n_{f}(t)}=\frac{n_{S}(t)}{n_{0}}
$$

The equation for risk is following (the risk is also known as failure rate or risk-rate, and it is associated with the conditions under which the unit is subjected):

$$
\begin{gathered}
h(t)=\lim _{\Delta t \rightarrow \infty} \frac{R(t)-R(t+\Delta t)}{R(t) \Delta t}=\frac{-R(t)}{R(t)} \\
=\frac{f(t)}{R(t)}, t \geq 0
\end{gathered}
$$

The meantime to fail:

$$
M T T F=E(t)=\int_{0}^{+\infty} t f(t) d t
$$

\section{Methods}

According to Fogliatto and Ribeiro [4], the main models used to describe reliability functions are exponential probability distributions, Weibull, gamma, lognormal, and reasonable. In the definitions of reliability analysis, it is necessary to determine which probability distribution best fits the data.

We presented a case study in which the data was collected from a company, and the reliability-centered maintenance technique was applied. We used Minitab v. 17 software for the graphs of the probability functions of some statistical models.

\section{Case Study}

The company studies is established in the State of Bahia, Brazil, in an industrial headquarters in Salvador city. This organization is a leader in the northeast region in the production of corn products, snacks, popularly known as "salty snacks". The factory is comprised of production lines and has approximately 200 employees working directly in production. The production line studied was "salty," following some definitions that characterize the process for the operation of the line.

Workday: Monday to Saturday from 10 PM to 6 AM; starting on Sunday at 10 PM and stopping on Saturday at 10 PM;

Three work shifts: Night, morning and afternoon;

The line consists of 4 machines;

Work directly in line production: 60 employees and 20 per shift;

The average day of 25 production days per month;

The start of the line production: Sundays in the night shift that starts at $10 \mathrm{PM}$, and the time is scheduled for $1 \mathrm{~h}$ to prepare the machines;

Every Tuesday: Service is held at 11AM for the staff, and all employees of the morning shift are released $1 \mathrm{~h}$ earlier so that they can attend. On Saturdays, the morning shift ends the operation of the line at $1 \mathrm{PM}$;

On Saturdays: The line is cleaned, so there is no production operation in the afternoon shift.

Table 1 shows the hours in daily hours of each work shift and defines the production operating hours of the line. It is possible to observe that the snack line operates at $19.33 \mathrm{~h} /$ day. 
Table 1. The shifts' workday.

\begin{tabular}{|c|c|c|c|c|c|c|c|c|}
\hline Shift & Mon & Tue & Wed & Thu & Fri & Sat & Sun & $\begin{array}{l}\text { Average hours } \\
\text { (round/day) }\end{array}$ \\
\hline Night & 6 & 7 & 7 & 7 & 7 & 7 & 7 & 6.83 \\
\hline Morning & 7 & 6 & 7 & 7 & 7 & 7 & 6 & 6.67 \\
\hline Evening & 7 & 7 & 7 & 7 & 7 & 0 & 0 & 5.83 \\
\hline Factory & 20 & 20 & 21 & 21 & 21 & 13 & 0 & 19.33 \\
\hline
\end{tabular}

Table 2 presents the data on the meantime between failures of the machine that compromises the snack food production line (hours per month).

Table 2. MTTF (h) of the snack line machine.

\begin{tabular}{lrrrrrrr}
\hline & Jan & Feb & Mar & Apr & May & Jun & Jul \\
\hline Supply Mat & 136 & 11 & 82 & 9 & 11 & 6 & 9 \\
Extruder & 367 & 217 & 22 & 29 & 32 & 35 & 96 \\
Packager & 211 & 269 & 420 & 101 & 158 & 124 & 180 \\
Oven & 80 & 50 & 30 & 20 & 15 & 14 & 10 \\
\hline
\end{tabular}

Table 3 provides information on cumulative data on maintenance service order quantities opened each month. Table 4 provides crucial information for directing the actions of the maintenance department, thinking of planning the workload for each available staff-hour.

Table 3. Number of occurrences.

\begin{tabular}{lccccccc}
\hline & Jan & Feb & Mar & Apr & May & Jun & Jul \\
\hline Supply Mat & 31 & 46 & 28 & 19 & 13 & 15 & 18 \\
Extruder & 39 & 24 & 10 & 25 & 20 & 9 & 20 \\
Packager & 115 & 125 & 80 & 93 & 87 & 25 & 30 \\
\hline
\end{tabular}

Table 4 and Figure 2 guide the prioritization of maintenance department actions for the equipment that most affects failures and to plan their workforce, staff-hours regarding the type of maintenance.

Table 4. The calls by maintenance type.

\begin{tabular}{lcccccrr}
\hline & Jan & Feb & Mar & Apr & May & Jun & Jul \\
\hline Electrical & 15 & 22 & 15 & 19 & 21 & 3 & 2 \\
Mechamical & 90 & 88 & 60 & 66 & 58 & 20 & 35 \\
Pneumatic & 10 & 15 & 5 & 8 & 8 & 2 & 3 \\
Total & 115 & 125 & 80 & 93 & 87 & 25 & 3 \\
\hline
\end{tabular}


Figure 1. Pareto of MTTF of the machine of the snack line.

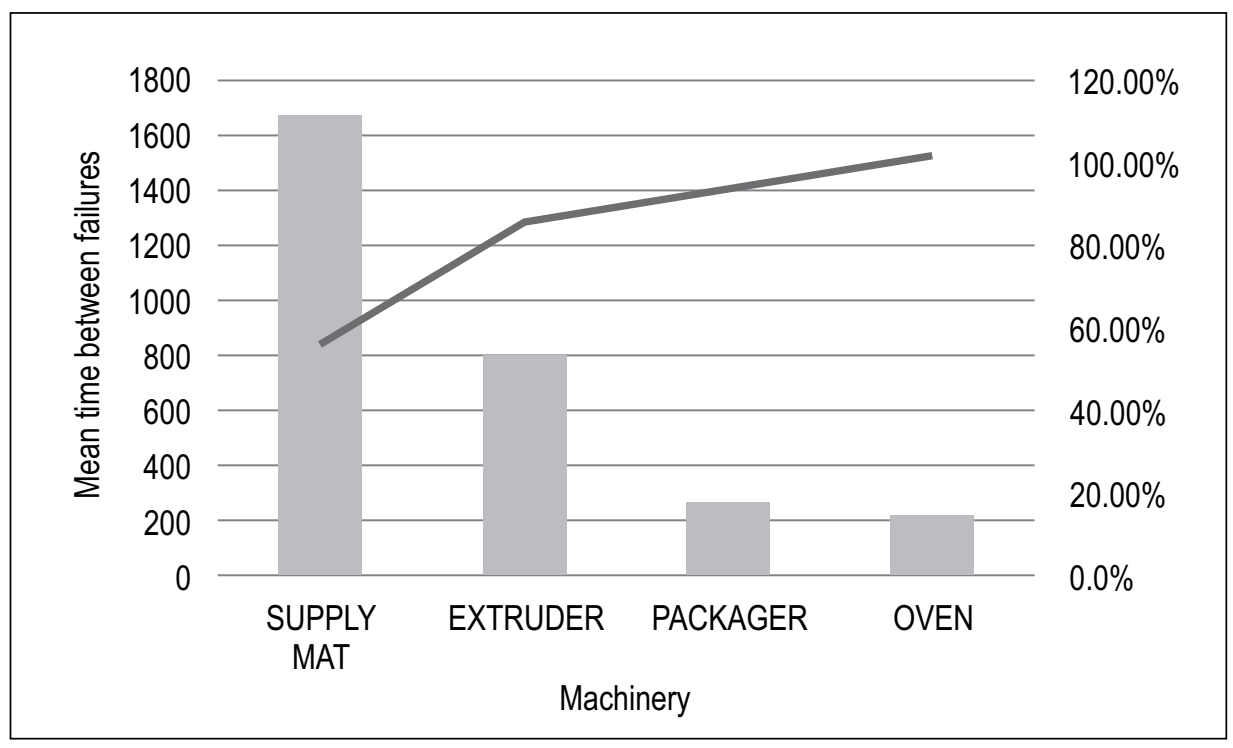

Figure 2. Priority Pareto by maintenance type.

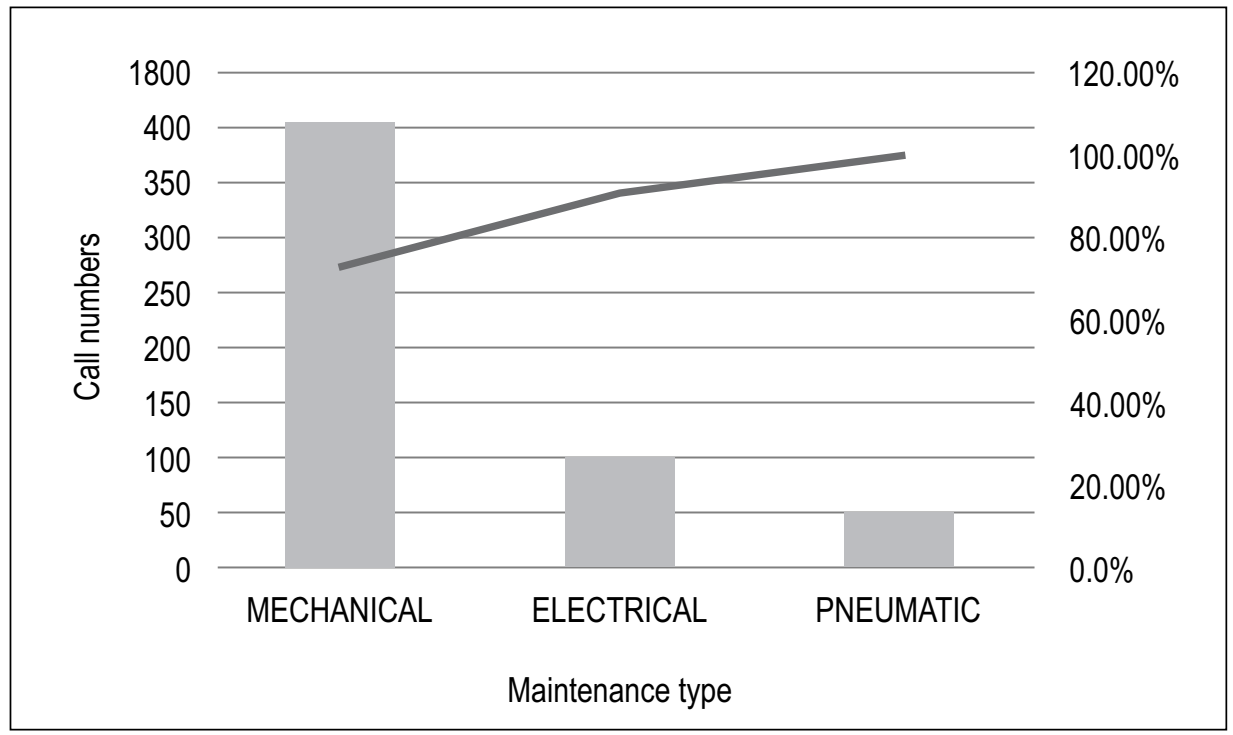

Based on Table 3 and Figure 1, the efforts should be addressed to the packing equipment with the robust performance of the mechanical maintenance team.

Table 5 presents the weekly MTTF (h) of the snack line wrapper due to the analysis of the graphical representation of Figure 1, demonstrating the importance of prioritizing the actions on the wrapper.
By applying the data from Table 5, we get to know the probabilistic model, which presents the best behavior.

For analysis and definition of the model, we used the Anderson-Darling test that serves to verify how well the data follows a distribution. By analyzing the values expressed in Table 6 for the Anderson-Darling test, we found that Lognormal is the probability model that best presents the distribution of data. 
Table 5. Weekly MTTF of the wrapper.

\begin{tabular}{ccccc}
\hline $\begin{array}{c}\text { Week 1 } \\
40\end{array}$ & Week 2 & Week 3 & Week 4 & Week 5 \\
& 35 & 45 & 51 & 40 \\
\hline Week 6 & Week 7 & Week 8 & Week 9 & Week 10 \\
68 & 67 & 67 & 68 & 70 \\
\hline Week 11 & Week 12 & Week 13 & Week 14 & Week 15 \\
130 & 100 & 120 & 50 & 20 \\
\hline Week 16 & Week 17 & Week 18 & Week 19 & Week 20 \\
20 & 11 & 35 & 46 & 48 \\
\hline Week 21 & Week 22 & Week 23 & Week 24 & Week 25 \\
30 & 35 & 37 & 40 & 13 \\
\hline Week 26 & Week 27 & Week 28 & Week 29 & Week 30 \\
39 & 25 & 28 & 31 & 30 \\
\hline
\end{tabular}

Week 31

27

The probability presented in the graphs (Figures 1 and 2) allowed the hypothesis test for suitability to a given distribution and made the analysis of the corresponding $\rho$ value necessary. If the value of $\rho$ is less than or equal to $\alpha$, which is the significance level $(\alpha=0.05)$, then the null hypothesis that the data followed the distribution is rejected. Minitab software for some cases does not always converge mathematically, so the Anderson-Darling test is used to calculate the p-value.

Based on the Anderson-Darling statistic values expressed in Table 6 and the analysis of the Figure 3 , we verified that the lognormal distribution presents the best approximation for the data. So lognormal is the distribution that represented the best model for the data.

Defining the probability distribution as lognormal, we apply the values to the reliability model using Eq. (5) to $\mu=3.70168$ and $\sigma=0.56858$.

$$
R(t)=1-\sigma\left(\frac{\ln (t)-\mu}{\sigma}\right)
$$

Therefore, considering $\mathrm{t}=100$ hours, we have $R(t)=0.47$, i.e., for every 100 hours, so we have a probability of 47 hours of the wrapper not breaking.

We calculated the meantime to fail, as Eq. (6) to $\mu=3.70168$ and $\sigma=0.56858$, resulting MTTF $=47.62$ hours.

$$
\text { MTTF }=e^{\mu+0,5 . \sigma^{2}}
$$

As the working day of the snack line is 19.33 hours, we have an MTTF corresponding to 2.5 days.

\section{Conclusions}

The present study sought through the technical application of the concepts of reliability and the use of real data, to support the national industry and demonstrate the importance of integration between companies and universities in order to develop technology and give durability and capability to industrial processes.

The machine analyzed in the packaging process (wrapper) had a reliability of $47 \%$, which is very low, as well as an MTTF indicator of 2.5 days. The machine is operated for three shifts for six days, 
Figure 3. Probability chart for failure.

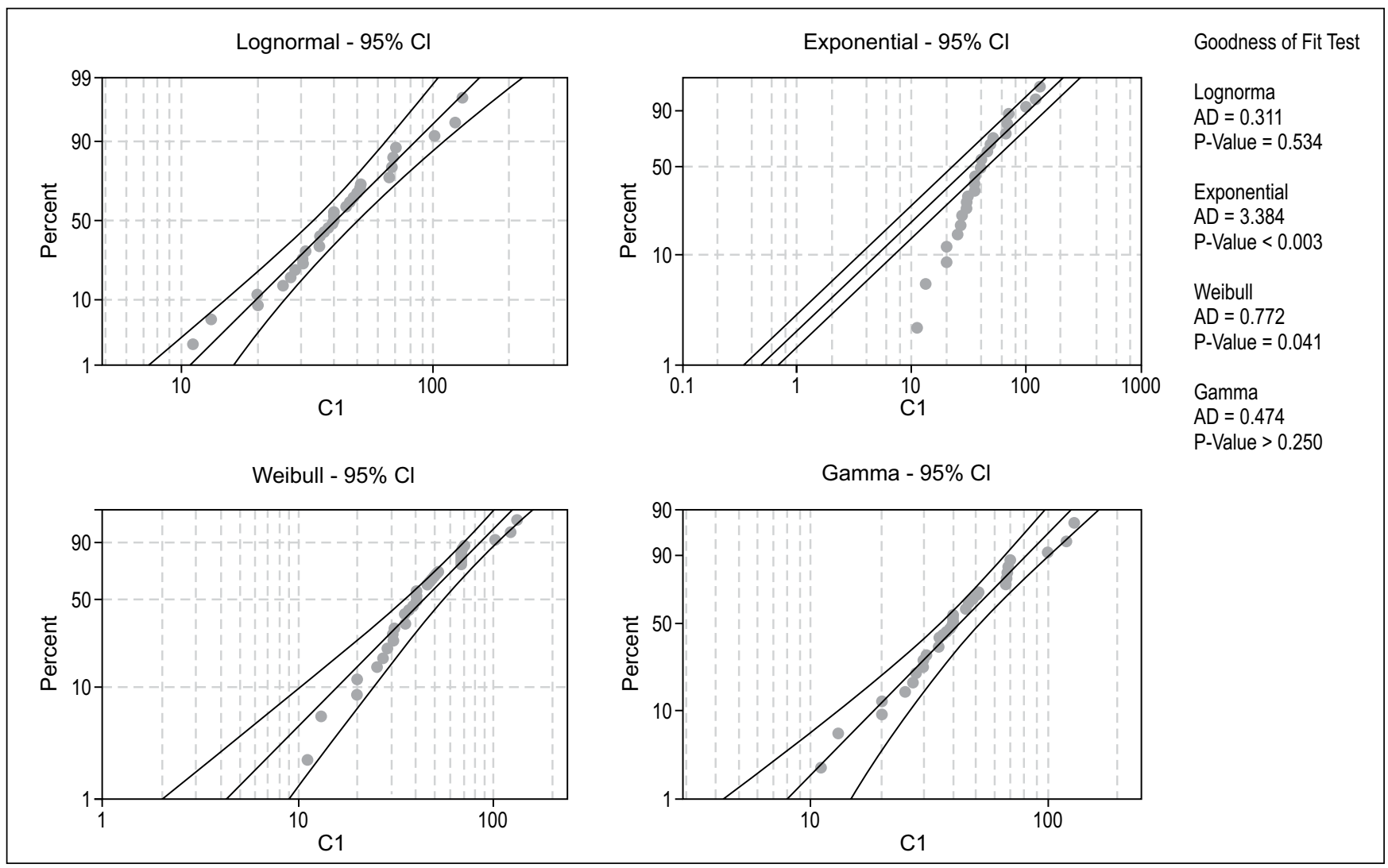

Table 6. Anderson-Darling statistic values for various distributions.

\section{Distribution}

Normal

Box-Cox Transformation

Lognormal

3-Parameter Lognormal

0.305

Exponential

2-Parameter Exponential

1.502

Weibull

0.772

3-Parameter Weibull

0.497

Smallest Extreme Value

2.851

Largest Extreme Value

0.448

Gamma

0.474

3-Parameter Gamma

0.540

Logistic

0.976

Log-logistic

0.235

3-Parameter Log-logistic

0.233

Johnson Transformation meaning that there will be probably two possible occurrences of mechanical failure in a working week.

\section{References}

1. Kardec, A., Nascif, J. Manutenção Função Estratégica, $2^{\mathrm{a}}$ edição, $1^{\mathrm{a}}$ Reimpressão 2004. Editora Quality Mark, Rio de Janeiro, Coleção Manutenção, Abraman.

2. Moreira, D.A. Administração da produção e operações. 2. ed. São Paulo: Pioneira, 2006.

3. Nowlan, F.S., Heap, H.F. Reliability-centered Maintenance. Technical Report AD/A066-579, National Technical Information Service, US Department of Comerce, Springfield, Virginia, 1978.

4. Fogliato, F.S., Duarte, J.L. Confiabilidade e Manutenção Industrial. Elsevier, Rio de Janeiro, 2009.

5. Siqueira, I.P. Manutenção Centrada na Confiabilidade: Manual de Implementação. 1. ed. Rio de Janeiro: Qualitymark, 2005. 408 p.

6. Xie, K., Cao, K., Yu, D.C. Reliability evaluation of electrical distribution networks containing multiple overhead feeders on a same tower. IEEE Trans. Power Syst. 2011;26:2518-2525. 